\title{
Behavioral Tests for Evaluation of Information Processing and Cognitive Deficits in Rodent Animal Models of Neuropsychiatric Disorders
}

\author{
Ales Stuchlik, Tomas Petrasek, Hana Hatalová, Lukas Rambousek, \\ Tereza Nekovarova and Karel Vales \\ Institute of Physiology, Academy of Sciences \\ Czech Republic
}

\section{Introduction}

Neuropsychiatric disorders represent a serious medical and human issue. In general, these diseases are detrimental to the quality of life and sociability of afflicted patients. Moreover, they are an immense socio-economic burden. Brain disorders are sometimes denoted as 'graveyards of pharmaceutical enterprises', referring to relatively a large proportion of drugs for these diseases failing to prove efficient or safe in later phases of clinical trials. Our understanding of what really happens in the central nervous system (CNS) is very limited, especially in relation to normal and pathological behaviors. This limitation also effects the research of neuropsychiatric disorders. We do not know the exact pathogenic mechanisms of numerous diseases, such as Alzheimer's disease or schizophrenia, which prevents the causal treatment of many of them. The symptomatic-like treatment often yields an insufficient therapeutic outcome and in many cases, is accompanied by serious side-effects (as is the case for classical antipsychotics in refractory schizophrenic patients). In some areas of neuro-science research, we are often just beginning to understand brain-behavior relationships in health and disease.

Aside from being a serious socio-economic and human challenge, many neuropsychiatric disorders involve deficits in mental and behavioral functions. These often reflect disrupted processing of information in the brain (such as gating deficits; more later), storage of information (learning and memory deficits, extending from working memory to long-term retention) and higher cognitive domains (such as impaired executive functions, cognitive control deficits). The diseased brain seems to process at least some information incorrectly, which contributes to the manifestation of the disease and may seriously alter behavior and the normal functioning of afflicted patients. Therefore, beside basic studies aimed at the nature of information processing and cognition impairments in human CNS diseases, important usage of behavioral tests lies in both screening for putative cognition-improving drugs and cognitive side-effects of established and novel pharmaceuticals.

Behavioral researchers in pre-clinical research conventionally use tests of information processing and sensorimotor gating, often tested with prepulse inhibition of the startle reflex (e.g. Bubenikova-Valesova et al., 2007), spontaneous behaviors (e.g. Palenicek et al., 
2007), latent inhibition tests and many others. In addition, not only memory scientists but also application-oriented researchers have often sought to examine higher mechanisms of cognition, such as spatial navigation and its changes in animal models and even in human patients (e.g. Hort et al., 2007). Moreover, spatial navigation to hidden goals (place navigation) has attracted much attention as a possible animal model of declarative memory (O'Keefe and Nadel, 1978). This is the domain traditionally ascribed only to humans representing the conscious remembering of facts and events.

This chapter will present some established tests in gating and information processing as well as several learning, memory and cognition tests. Beside sections dedicated to classical spatial navigation tests (i.e., the Morris water maze and radial maze), we will present some past and recent behavioral tests of navigation in dynamic environments and cognitive coordination and discuss their usage in animal models.

\section{Animal models}

Animal models of neuropsychiatric disorders represent an extremely useful approach in the research of both the neurobiology and treatment of CNS disease. When considering CNS diseases, animal models can be defined as (usually experimental) interventions into CNS or brain function. These manipulations often project specific and unusual behaviors. These may be straightforward hyperlocomotion in a pharmacological model of schizophrenia induced by NMDA receptor antagonists or compulsive adherence to specific routes and objects in animal models of obsessive-compulsive disorder (OCD induced by repeated systemic treatment with quinpirole, a D2-like receptor agonist. (Szechtman et al., 2001, Dvorkin et al., 2008; Dvorkin et al., 2010; Woody and Szechtman, 2011). Nevertheless, they should not be anthropomorphized (such as a 'diseased rat') but have the purpose to serve as model reproductions in laboratory animals of specific classes of symptoms of CNS disorders, rather than a disorder as a whole, despite common usage of the term of animal models in the latter .

It is obviously impossible to reproduce the full symptomatic and causal spectrum of human neuropsychiatric disorders in laboratory animals. However, results from these models allow for investigating potentially beneficial drugs, beside often significantly contributing to the understanding of the disease. Animal models of neuropsychiatric disorders are usually evaluated according to criteria of validities. The 'resemblance' between the animal model and human pathological phenotypes is usually termed as face validity, related to similar pathophysiology and strong phenomenological similarities between (often aberrant) behaviors of an animal and specific symptoms of the human condition. Evaluation of whether the different behavior in different species reflects similar underlying processes is a question of construct validity (Ellenbroek and Cools, 1990). In general, the construct validity refers to a correlation between the theorized outcome of measuring and measuring itself. Construct validity is therefore more relevant, as it relates to similarity in the underlying neurobiological mechanisms that are involved in particular behavior. The precise expression of the behavior could be different in human and in experimental animal models. The concept of construct validity is closely related to etiological validity. A model shows etiological validity if the etiology of the disease in the human and animal model is the same (Tordjman et al., 2007). However, to model particular psychopathology it is necessary to specify which is the core process postulated to be common to the disorder and to the model. 
It is difficult to assess etiological validity for complex human disorders, such as neuropsychiatric disorders, because so little is known about the etiology of the illness. Predictive validity generally refers to the extent to which the outcome of one measurement predicts the outcome of another measurement or some other criterion. In biomedical research, it refers to the predictive value that observations made in animals could have for the conditions in humans. It can be applied to various situations, but in practice, the predictive validity of animal models in psychopharmacology is primarily used in a narrow sense to refer to the ability of a model to identify drugs with potentially therapeutic value for humans. (Wilner, 1991). Reliability applies to the accuracy with which the observations, both clinical and experimental, are made.

Together with other human disorders, neuropsychiatric disorders and especially accompanying deficits in information processing and cognition share the urgent necessity to find appropriate and sensitive animal models even if limited. Nevertheless, because the neuropsychiatric disorders affect mostly features and conditions considered as typically human, the modeling of psychiatric conditions could be the most difficult and cannot be reproduced exactly in the rodents. However, there is hope for more specific behavioral approaches which can be used in any rodent animal models of cognitive disruption and which will be presented in the main chapter.

\subsection{Tests of sensorimotor gating}

Deficits in gating functions and signal processing are often found in neuropsychiatric disorders and their animal models. It has been proposed that they might contribute to impaired cognitive functions. The topic has been covered by a number of excellent reviews (e.g. Geyer 2008, Swerdlow et al., 2008; Castagné et al., 2009). A classic example of the gating paradigm is auditory 'sensory gating', in which two audible pulses (clicks) are presented to a subject in a conditioning-testing manner and its P50 event-related potentials are measured (Adler et al., 1982; Adler et al., 1986; Martin et al., 2004; Martin and Freedman, 2007). In normal subjects (both rats and humans), the potential response to the second stimulus is diminished (Adler et al., 1982; Adler et al., 1986), reflecting insufficient habituation (reviewed in Geyer, 2008). It was demonstrated that a deficit in this sensory gating was present in schizophrenia patients (Adler et al., 1982) and in rats in the animal model of schizophrenia (Adler et al., 1986). Moreover, this phenomenon is also disrupted in manic patients with bipolar disorder (Franks et al., 1986; Baker et al., 1990). This paradigm also significantly contributed to the concept of the beneficial effects of alpha-7 nicotinic agonists in schizophrenia (Martin et al., 2004; Martin and Freedman, 2007).

Perhaps the widest testing of sensorimotor gating as a measure of information processing is the prepulse inhibition (PPI) of the startle reflex, elicited by a strong sensory stimulus, usually a sound, but other sensory modalities may be considered as well. Since the test involves a motor component (startle reflex), it can be viewed as a true sensorimotor gating paradigm. If the prepulse (which is not capable of eliciting a startle reaction) is presented at an appropriate interval (usually $30-500 \mathrm{~ms}$ ) before the pulse, subsequent reduction of the startle due to a prepulse is considered a measure of sensorimotor gating. Its disruption (meaning that subject exhibit strong startle reaction even after administration of both prepulse and pulse) is found in several CNS disorders such as Alzheimer's disease (Hejl et al., 2004; Ueki et al., 2006), schizophrenia (Braff et al., 1992; van den Buuse, 2010; reviewed in 
Braff and Geyer, 1990), and bipolar disorder (Rich et al., 2005; Giakoumaki et al., 2006), but reports have been published also on disrupted PPI in obsessive-compulsive disorder (OCD; Hoenig et al., 2005) or attention deficit/hyperactivity disorder (ADHD; Castellanos et al., 1996; Conzelmann et al., 2010).

Perhaps the most abundant usage of the PPI test in humans and animals relates to schizophrenia. It was proposed that deficits in information processing and the impaired ability to distinguish between irrelevant and relevant information belongs to core symptoms of this disease (Ellenbroek and Cools, 1990). As the test is fully applicable to both rats and humans, it allows direct comparison of sensorimotor gating deficits in human patients and laboratory animals. In animal models of CNS disorders, an experimental disruption of PPI is usually induced by pharmacological or neurodevelopmental manipulations. The PPI is disrupted after application of dopamine agonists, such as apomorphine and amphetamine ( Mansbach et al., 1998; Auclair et al., 2006), N-methyl-D-aspartate (NMDA) receptor antagonists such as ketamine, phencyclidine or MK-801 (Mansbach and Geyer, 1989; de Bruin et al., 1999; Bubenikova et al., 2005a; Bubenikova-Valesova et al., 2007), but interestingly also after treatment with MDMA (Bubenikova et al., 2005b), serotonergic hallucinogens (Ouagazzal et al., 2001; Palenicek et al., 2008) or scopolamine (Jones and Shannon, 2000; Thomsen et al., 2010). Neurodevelopmental procedures such as isolated rearing (Geyer et al., 1993; Bakshi et al., 1998), maternal deprivation (Ellenbroek et al., 1998; Ellenbroek and Cools, 2000) and neonatal lesions of the ventral hippocampus (Sams-Dodd et al., 1997; Len Pen and Moreau, 2002) also affect this phenomenon. These changes in animal models can be, in some cases, reversed by anti-psychotic treatment (e.g. Bakshi et al., 1998; Len Pen and Moreau, 2002; Bubenikova et al., 2005a). PPI can be also successfully applied to genetically modified mice in animal models (Geyer et al., 2002; Powell et al., 2009).

When considering the usefulness of PPI in animal models of schizophrenia and other psychiatric disorders, one must consider several important points. The PPI paradigm is fully translational, i.e., it can be feasibly used both in laboratory rodents and humans, which facilitates direct comparison of gating deficits in human CNS disorders and their animal models. This is a significant advantage of the test, although it is not the only translatable task out of the plethora of tests used in animal models. The test is also quite simple and basic gating deficits can be expected to reflect complex impairments of informational processing, which may lead to cognitive deficit. However, when interpreting the results of PPI experiments, it should be emphasized that the test is perhaps too simple to reveal memory or cognitive impairments. In memory terms, PPI is essentially a modification of reflex behavior (startle). Despite this limitation, the prepulse inhibition of the startle reflex is abundantly used and a very informative behavioral paradigm for gating mechanisms studied in animal models of CNS disorders.

\subsection{Behavioral tests of learning, memory and cognitive functions}

Behavioral tests for the assessment of learning and memory (and other types of cognitive domains, such a the cognitive coordination, more later) belong to powerful tools in the hands of researchers focused on animal models of neuropsychiatric disorders, their brain and behavioral deficits. They have also significance for scientists focused on procognitive drugs. Beside these functions, spatial orientation or place navigation (i.e., navigation to directly imperceptible goals) belong to central models for studying cognitive deficits in 
experimental animals. Navigation to (or away from) invisible goals can be provided by two complementary processes: allothetic (allocentric) and idiothetic (egocentric) orientation (Mittelstaedt and Mittelstaedt., 1980; Mittelstaedt and Glasauer, 1991). Many forms of spatial navigation depend on the hippocampus both in rats (Morris et al., 1982) and humans (Maguire et al., 2006). Indeed, neurons exist in the hippocampus and interconnected structures of rodents that produce firing depending on complex environmental features such as spatial position (place cells, O'Keefe and Dostrovsky, 1971), or direction (head direction cells, Taube et al., 1990a,b). Other important cell types such as grid cells in the medial entorhinal cortex (Hafting et al., 2005), border cells (Solstad et al., 2008), boundary vector cells (Level et al., 2009), goal cells (Hok et al., 2005; 2007) and others, as well as neurons with mixed properties, have recently been discovered.

The following sections will present several selected tests of learning and memory which were tested or have promising potential in the research of pre-clinical animal models. Our selection must be subjective. Many important tests are reviewed elsewhere in scientific literature. Every test is presented in the context of the specific behavioral function that it involves and the significance for the study of animal models is at least briefly discussed.

\subsubsection{Morris Water Maze (MWM)}

The Morris water maze (MWM) is the classic, and probably most widely used test of spatial learning and memory. The apparatus was designed by Richard G. Morris in 1981 (Morris, 1981, Morris, 1984). It represents a circular maze with larger diameter (e.g. 180 $\mathrm{cm}$ ), filled with opaque water, in which a rodent (typically a rat), released from various locations on the pool periphery, searches for an escape platform hidden under the water surface. The trial usually stops either when a rat has found the platform, or after a defined maximum duration is completed (e.g. $60 \mathrm{~s}$ ), after which the animal is gently guided to it. In any case the animal is allowed to stay on the platform for fixed period of time (e.g. 15 s). This test is unique in that virtually all proximal (olfactory etc.) cues are hidden (the animal swims in the water) and only the distal, landmarks outside a pool can be used to localize the platform in a 'cognitive map-like' fashion (in the classical version). In addition, the test uses the natural ability of rats to swim while not causing a major distress to the animals despite a significant stress response induced by the task (Hölscher, 1999; D'Hooge and De Deyn, 2001). Another advantage of the test is its simplicity; which has contributed significantly to its success and massive use. The behavior of rats in the Morris water maze can be evaluated by many criteria. Beside escape latency, i.e., the time needed to find the platform, swim speed and path length should be analyzed in order to control for this factor, which may also provide an indication of sensorimotor or motivational impairments. In many cases, the total path to the platform provides a better solution than escape latency. It is also preferred to use a measure of thigmotaxis, such as time spent at the wall. This has proven to be very useful in assessing behavioral strategies in these tests (e.g. Garthe et al., 2009). There are a number of other measures, including direction angle, Whishaw error etc., which are reviewed elsewhere. Generally the design, use and aspects of the MWM has been reviewed in several papers (e.g. McNamara and Skelton, 1993; D’Hooge and De Deyn, 2001; Clark and Martin, 2005).

The Morris water maze is typically used in two basic experimental protocols: The reference (or long-term) memory version (also incremental version or place version; reviewed in Clark and 
Martin, 2005) involves the training of rats released from the periphery of the pool to find a hidden platform, the position of which is stable across daily sessions. There are usually more swims (trials) in daily sessions, e.g. 8, 10 or 12. The learning in this task is incremental, and healthy animals of the Long-Evans strain from the breeding colony of the Institute of Physiology, AS CR usually reach the asymptote escape latency by the fourth daily session (with 8 swims; Stuchlik et al., 2004; Vales et al., 2006; Stuchlik et al., 2007a). An early study by Morris showed that place navigation in this version is impaired by a hippocampal lesion. However, this version can also be made hippocampus-independent as well as resistant to several pharmacological manipulations after extensive pre-training or specific training protocols. An interesting procedure is the so-called non-spatial pre-training (NSP; Saucier et al., 1996; Cain et al., 1997) in which animals are first made familiar with all procedural aspects of the task ('rules'), such as that the platform is in the maze. There is no way to get on the wall etc. The pre-training is usually pursued by closing a dark curtain (without any cues) around the pool and putting the submerged platform in random places in the pool. Animals thus get fully acquainted with searching for the platform, but do not know where to search. Such pre-training was found to eliminate a number of deficits, such as after NMDA receptor and cholinergic blockade (Saucier et al., 1996; Cain et al., 1997), serotonin depletion (Beiko et al., 1997) or diazepam treatment (Cain, 1997).

Another variant of the Morris water maze task is a delayed-matching-to place version (DMP; Steele and Morris et al., 1999, O'Carroll et al., 2006), in which animals are released in four trials a day and the platform position is changed between days (but always stays the same within four trials in a particular day). Therefore, the rat cannot locate the platform correctly or find it just by chance in the first swim every day. However, a second swim already contains a memory trace from the first one and typically this swim is evaluated. Moreover, multiple inter-trial intervals (ITIs) between the first and second swims can be used (e.g. 15s; $20 \mathrm{~min}$ and $90 \mathrm{~min}$ ). There should be no interference between positions in particular days, i.e. each position should be used only once. The task represents a paradigm for the assessment of one-trial spatial learning. With short delays (e.g. $15 \mathrm{~s}$ ), this modification is essentially a test of spatial working memory and longer delays may be used for evaluating the persistence of the memory trace (O'Carroll et al., 2006). The DMP test in the Morris water maze is strictly hippocampus-dependent, meaning that animals with a hippocampal lesion were not capable of improving from the first to the second swim and thus failed to learn (Steele and Morris, 1999) even after extensive experience with the maze.

The Morris water maze, as in other learning and memory tasks, requires a control for a confounding effect of a more general impairment, such as in perceptual, motivational and procedural functions. This can be tested by a control test, visible platform test, in which the platform is raised above the water and animals are allowed directly to it. Moreover, performance in the spatial versions should be well analyzed for sensorimotor and other measures in order to detect a 'non-cognitive impairment.' After completion of the whole training or even after each daily session (Markowska et al., 1993), a 'probe trial' may be performed, during which a rat is allowed to swim freely in the pool and to show a potential preference for a given zone, e.g. time in cardinal quadrants of the maze or number of crossings through the previous platform location. Scientists sometimes use various and more sophisticated designs of the basic MWM configurations, with analyses of behavioral strategies (e.g. Garthe et al., 2009). 
The MWM has become a benchmark test for learning and memory deficits in animal models and preclinical research in general. In the context of the use of this test, it might be emphasized that there are also other modifications and protocols including a 'working memory version' (e.g. eight swims daily with the target position changed between days (Rezacova et al., 2011))- However, this might be confounded by long-term memory, versions using insets (annular water maze), versions with on-demand or an Atlantis platform (Buresova et al., 1985; Spooner et al., 1994) and some studies aiming at an assessment of 'self-motion' or 'idiothetic' navigation (Moghaddam and Bures, 1996;1997) or path integration (Benhamou, 1997) in the MWM. Testing of the working memory in the MWM is required due to information processing and working memory deficits in many CNS disorders, such as schizophrenia (e.g. Van Snellenberg, 2009).

A relevant notion for animal models in the MWM is the influential and strongly corroborated concept that the MWM does not undergo systems consolidation, supported by the fact that hippocampus ablations disrupted the memory in the MWM any time after acquisition, both for recent and remote memories (Clark et al., 2005; Martin et al., 2005, Broadbent et al., 2006), which contradicts the view of a transfer of memory trace from hippocampus to neocortical areas, at least in this task (reviewed in Kubik et al., 2007). Athough, the test is widely used to assess the properties of established potential antipsychotics in animal models of schizophrenia (Bubenikova-Valesova et al., 2008a,b; van der Staay et al., 2011; reviewed in Castagné et al., 2009), antipsychotic drugs impair memory in the Morris water maze in naive rats (Skarsfeldt, 1996).

\subsubsection{Radial maze}

The radial maze (or radial-arm maze) is a classic behavioral test employing spatial cognition as a model for the study of memory, learning and the effects of drugs or gene manipulation. The method is a standard of spatial memory research. The maze was invented by Olton and Samuelson in 1976 (Olton and Samuelson, 1976). This task rapidly became popular and widely used in behavioral neuroscience research. In the original version, the maze had a central octagonal platform and eight arms of the same length. The 'standard version' of the maze, which is conventionally used, consists of a platform and identical arms radiating from the platform spaced at regular angles - the number of arms is usually eight, but other versions are used as well: e.g. four arms - this maze is known as the 'plus maze' (Zeldin and Olton, 1986); twelve arms (Cook et al., 1985), seventeen or even twenty four (Buresova and Bures, 1982). The radial maze apparatus is commonly elevated above the floor and placed in a room with many salient visual cues that can be used for allothetic orientation. In the standard version, similar to the initial Olton experiment, the maze is fully baited, which means that at the end of each arm are placed food rewards. An animal has a limited time or an amount of choices, therefore the optimal strategy in a fully baited maze is to visit every arm only once. There are numerous interesting modifications of the radial maze, such as an aquatic version using aversive stimuli rather than appetitive stimuli (Buresova et al., 1985), or a version combining but dissociating both win-shift and win-stay strategies (Packard et al., 1989).

Many parameters can be used to evaluate behavior and memory in particular in the radial maze - the fundamental and the most apparent is the number of errors. We define an error as a return of the rat to the previously visited arm. Another parameter is the rank of the first 
error - the number of consecutive correct responses before an error occurs. These two parameters evaluate the efficiency of animals in the test. With training the number of errors decreases and the rank of the first error increases. To illustrate not only their efficacy but also their strategies, it is possible to quantify the angles between two successfully visited arms (Dubreuil et al., 2003). Another parameter is the degree of divergence (AmmassariTeule and Caprioli, 1985), which is counted only for successful trials with no errors, and the degree of difference is counted as the number of arms between two subsequent correct choices plus one. The number could be averaged for trials during the whole daily session. Degree of divergence equals 7 if rats are using a clockwise strategy, which means they visit systematically all 8 arms. Other parameters include e.g. the sequential position of error which determines relative probability of repetition of choice (Olton and Samuelson, 1976). For each animal and each day, the first seven choices are ordered (the eighth choice is not considered because after this choice the session is ended and there is no opportunity to repeat a choice). The observed relative probability of repeating the correct choice is calculated. Scores could range from 0 to 100 percent. 100 percent indicates that all errors are made by repeating this position, 0 percent indicates that this choice was not repeated. The results show that animals have the tendency to make errors in the arm they chose at the beginning of the session. In the original Olton version all arms were initially open and rats could freely explore all of them without any restrictions.

In the late seventies, Olton and his colleagues introduced a new version of the task with inter-choice time intervals, where the access to the arms is prevented (confinement intervals) (Olton, 1979; Olton et al., 1980). Olton implemented this step to prevent rats from stereotypic behavior which he observed. However, the literature reports the use of both versions of the radial maze: with and without confinement. Dubreuil systematically tested the performance of rats in the maze without and with confinements of different durations (Dubreuil et al., 2003). They found that both groups - without confinement and with confinement of $10 \mathrm{sec}$. reached a similar efficiency after 12 days of training, although the confinement group made more errors during the training. However, even with a similar level performance rats from a different group could use different behavioral strategies to solve the task. The rats from the no-confinement group used (at least in some sessions) a clockwise strategy, thus they visited, systematically, all the arms. It seems that confinement prevents development of this strategy. Furthermore, the rats from the confinement group did not show any preference for a particular angle. The author supposed that a clockwise strategy is based on locomotor activity and that implementation of few seconds of delay is necessary to disrupt this motorbased strategy and allow animals to develop a spatial representation of the environment. Confinement intervals could range, in different versions of radial mazes, from seconds to minutes or tens of minutes (e.g. Dubreuil et al., 2003, Bolhuis et al., 1986). The original fully baited version of radial maze is designed to assess the working memory of animals. It is important to emphasize that the term 'working memory' could be used with slightly different meanings for humans than for animals. Despite the differences, it seems that the animal concept of working memory is in accord with the human models in some respects (Keeler and Robbins, 2011). In a broader sense working memory in animals could be defined as a representation of object, stimulus or spatial location which is used to guide a behavior and is typically used within one testing session (Dudchenko, 2004). It could be problematic to distinguish working memory from other subtypes of short-term memory, but it is 
distinguishable from reference memory, a system of long-term memory. To test reference memory and working memory at the same time, a modified version of the radial maze was developed (Olton and Paras, 1979). This maze contains two sets of arms and only one of these sets is baited. The same arms contain food every day during the training. An animal has optimal performance when entering each of the baited arms only once on each trial and avoiding the unbaited set. The set which never contains the food represents the test of 'reference memory' and entry to a never-baited arm is a reference memory error. The other arms containing the food constitute standard working memory test and repeated entry to one of these arms within one session is considered to be a working memory error.

In the context of neuropsychiatric disorders and their animal models, the radial maze has much attraction and is conventionally used to detect deficits in spatial working and reference memory in rats. A disadvantage of the test is that it may involve motor (or praxis) strategy of going successively from one arm to another, but this can be overcome by introducing a confinement interval between particular choices. Another issue could be the potential use of olfactory cues that indicate which arms have already been visited. Various methods to prevent the using of olfactory cues may be applied: it is possible to allow animals freely explore the maze before the test, thus the maze is saturated with aromatic cues; it is possible to clean the arms between the choices or to rotate them around the platform while the positions of the food remain the same (Sharma et al., 2010). The Olton radial maze has many advantages: it allows a study of several cognitive phenomena according to the experimental design that is used. The test is standardized and could be easily repeated in different laboratories. As mentioned before, spatial cognition is an intrinsic property of animal cognition and rodents could acquire the task quite easily. Moreover, the standard version of radial maze is appetitive and causes little stress to animals, except for the food restraint. The opportunity to separate working and reference memory and precisely quantify their deficits makes the radial maze powerful tool to model and study human neuropsychiatric disorders on their animal models, including schizophrenia, Alzheimer's disease, etc.

\subsubsection{The Carousel maze}

The Carousel maze (previously also termed active allothetic place avoidance (AAPA) or active place avoidance task (Stuchlik et al., 2004; Stuchlik and Vales, 2005; Vales et al., 2006, Stuchlik et al., 2009; Bubenikova-Valesova; 2008) or Room+/Arena- task (Weiserska et al., 2005; Kubik and Fenton 2005) is a variant of the place avoidance task (Bures et al., 1997, Bures et al., 1998; Fenton et al., 1998, Cimadevilla et al., 2000a,b,c; 2001a,b,c), in which a rodent (typically a rat, but the maze can be used with mice as well; Cimadevilla et al., 2001a) is placed on a smooth circular arena and required to avoid a directly imperceptible to-beavoided sector. In the Carousel maze, the experimental arena slowly continuously rotates (1 $\mathrm{rpm})$ in a lighted room and the to-be-avoided sector $(60 \mathrm{deg})$ is defined in the fixed position in the coordinate frame of the room. Rats must therefore recognize the distal visual cues in the room, navigate according to them and ignore self-generated arena-based cues (urine, droppings, scent marks) which are dissociated from the to-be-avoided sector position by arena rotation. Animals also perceive arena rotation (which facilitates learning; Blahna et al., 2011) and have to find an appropriate active strategy moving constantly or in interrupted runs in the safe part of surface (hence active place avoidance). Behaviors in the Carousel 
maze can be evaluated by many parameters. The most frequently used measures include total distance traversed per session (as a measure of locomotion), number of errors (i.e., the number of entrances into the sector) and maximum time between two errors (maximum time avoided) showing cumulative performance within a session. The latency from the session start to the first error (latency to first error) shows the memory trace established on the previous day and thus can serve as a measure of retrieval of avoidance and may be suggestive of memory retrieval. There are additional measures which may characterize the track in a quantitative way (linearity of the trajectory, dwell-time in particular radial and annular zones, total number of shocks, percentage of time spent in the target quadrant and its counterparts and 'radial histogram' measures). Many such parameters are provided by a formula for the place avoidance arena (Tracker, TrackAnalysis, Biosignal Group, USA).

\subsubsection{Development of place avoidance tasks and Carousel maze}

The original 'place avoidance' tasks were developed in the late nineties (e.g. Bures et. al., 1997). The design of a 'dry-land' spatial maze brought several major advantages:

1. It facilitated place-cell recordings (although the first, but very important paper on place cells' behavior in a two-frame place avoidance task was published no earlier than 2010; Kelemen and Fenton, 2010).

2. It tested animal spatial learning and memory capabilities in a more natural environment than the Morris water maze, which later turned out to be a convenient tool in animal models of schizophrenia (Stuchlik et al., 2004; Stuchlik and Vales 2005, Vales et al., 2006; Bubenikova-Valesova et al., 2008, Vales et. al., 2010).

3. These tasks together with the selective usage of a constantly rotating arena and light/dark conditions allowed the definition of a to-be-avoided sector in the coordinate frames of either room or the arena (these two might be dissociated by slow arena rotation). This strongly advanced scientific views on the organization of information into the reference frames and the role of hippocampus (Fenton et al., 1998; Cimadevilla et al., 2001a) and ultimately to the discovery of a 'cognitive coordination' function of the hippocampus (Wesierska et al., 2005). This showed that this 'frame-segregation' function of the hippocampus is dissociable from the navigational function (Kubik and Fenton, 2005). Moreover, the aforementioned electro-physiological paper (Kelemen and Fenton, 2010) provided evidence for a neural substrate of cognitive control in this structure, showing that representations of the arena and room frames alternate in the hippocampus during solution of the two-frame place avoidance task requiring simultaneous avoidance of dissociated room and arena sectors. It is noteworthy that the Carousel maze was the task in which a blockade of maintenance phase of long-term potentiation (LTP) was found to erase a previously established memory trace as first (Pastalkova et al., 2006).

4. In particular, the Carousel maze has proved to be a suitable test of altered behavior in animal models of brain disorders, mainly schizophrenia (a pharmacological model induced by systemic treatment with a psychotomimetic MK-801, a non-competitive NMDA receptor antagonist) and has been used in several animal model studies todate (Stuchlik et al., 2004; Stuchlik and Vales, 2005; Vales et al., 2006, Bubenikova-Valesova et al., 2008, Stuchlik et al., 2009, Vales et al., 2010). Notably, the task was not found to be sensitive to an electrolytic lesion of the posterior parietal cortex (Svoboda et al., 2008), but is dependent on an intact retrosplenial cortex (RSC; Wesierska et al., 2009). More 
specifically, the versions that involve conflict or motion of frames are impaired suggesting a role of the RSC in cognitive coordination.

\subsubsection{Properties of the place avoidance and Carousel maze}

It has been shown that rats learning the place avoidance tasks are capable of simultaneous and independent knowledge for arena- and room-frame memories (or representations; Fenton et al., 1998) and variants of the place avoidance tasks generally include those with no conflict in these two frames (e.g. both frames stable, or one artificially suppressed, see Wesierska et al., 2005) and modifications involving a conflict between frames. This is the case of the Carousel maze, where the arena and information based on its surface rotates, whilst the lighted room and to-be-avoided sector are stable. Hypothetically, a similar conflict of frames would occur in the avoidance of the to-be-avoided sector rotating together with the arena (defined in the arena frame) in the stable room. The ability to organize two dissociated references frames reflects a cognitive coordination function (see above). Passive versions of the task (where the animals do not have to actively move in order to solve it efficiently) are usually used with so-called 'pellet-retrieval' (or pellet-chasing, Muller, 1996). This means that food-deprived avoiding rats are trained to collect small food pellets periodically dispersed onto random places of the arena floor from an overhead feeder. Contrary to passive versions, in the active versions of the task, such as the Carousel maze (active place avoidance), or a Carousel maze with shallow water suppressing the disturbing intra-maze cues (conflict between frames minimized), it is not necessary to motivate the animals to collect food, however, our experience suggests that random collecting for the scattered food during avoidance gives less variability in data and provides a sharper resolution for drug effects. However, it should be noted that this procedure failed to be useful for mice, which are usually tested on the arena covered with a grid.

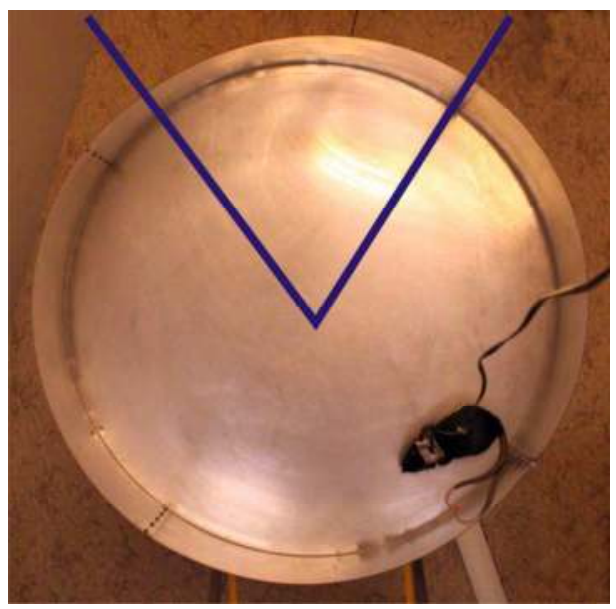

Fig. 1. A laboratory rat in the Carousel maze. The arena rotates and a to-be-avoided sector is defined in a particular part of the arena. The sector is unmarked (directly imperceptible), it is defined solely by the tracking program, it is delineated by the blue line in the figure. 
The Carousel maze is a specific spatial learning task in several aspects. The sector is defined with respect to distal room cues, so the animals are required to use a purely allothetic (Mittelstaedt and Mittelstaedt, 1980) strategy for determining its position. The allothetic mode of information consists of distal orienting, mainly visual cues. It has been demonstrated that rats cannot acquire this task in darkness (unpublished results). The idiothetic mode of navigation (referring to the collection and integration of self-motion signals, (Mittelstaedt and Mittelstaedt, 1980, Mittelstaedt and Glasauer, 1991) and substratal exteroceptive cues such as scent marks which are normally crucial for learning on a dry arena; (Stuchlik et al., 2001; Stuchlik and Bures, 2002) are irrelevant and animals need to ignore them. Another feature of the task is that it requires an active approach for successful avoidance behavior. Passive strategies such as freezing or simple escape upon shock exposure represent an inefficient strategy, since arena rotation repeatedly transports the rat into the shock sector if the animal does not actively avoid it. The typical strategy to avoid punishment is to recognize the position of the shock sector and stay away from it by walking in a direction opposite to arena rotation. Another advantage of the task is that it is acquired very rapidly (depending on the variant, even faster than in the Morris water maze or radial maze). It is therefore possible to assess even short-term changes in performance of animals, e.g. during the oestrous cycle (Cimadevilla et al., 2000b). Since the Carousel maze is a dry-arena task, it does not require swimming and thus can be applied to as young as weanling rats (Cimadevilla et al., 2001b).

Very straightforward support for the usage of the Carousel maze and place avoidance tasks in general in the research of animal models comes from a study of Abdel Baki et al., 2009. Instead of using single-condition avoidance, the authors designed a hierarchy of place avoidance tasks consisting of passive and active versions with incrementally increasing demand for the segregation of frames and showed that this battery is capable of discriminating between mild and moderate brain injury (Abdel Baki et al., 2009). Indeed, for use in animal models, (which is favorable, the test is rapidly acquired by intact rats; Stuchlik et al.,. 2004) it should be emphasized that it is preferable to use more conditions of the place avoidance with different requirements for frame segregation, either successively as in lesion and neurodevelopmental models; (Abdel Baki et al., 2009; Stuchlik et al., 2011) or in different animals (for drug treatments). This allows for interpretation of data in terms of the cognitive coordination hypothesis (see above) rather than mere acquisition of room-based place avoidance on the rotating arena. We propose that pure acquisition of the Carousel maze task such as used in Stuchlik et al., 2004; Vales et al., 2006; and Stuchlik et al., 2009 represents a mixture of contribution in allothetic learning, skill learning (Dockery and Weiserska, 2010) and coordination of arena and room frames (Wesierska et al., 2005, Kubik and Fenton, 2005, Kubik et al., 2006). It is recommended to pursue a pre-exposure (habituation) to the environment. Some form of pre-training prior to manipulations should be also considered (Stuchlik and Vales, 2005; Vales and Stuchlik, 2005). Performance in the Carousel maze was demonstrated to be overtly impaired also by NMDA-induced lesion of the dorsal hippocampus as a model of excitotoxic damage to the brain (Rambousek et al., 2011), such as in the case of ischemia or stroke. In some cases, however, the locomotor activity in the Carousel maze was found to be altered by lower doses of drugs than spatial avoidance parameters (Stuchlik et al., 2007b). Therefore, it is favorable to design tests without locomotor components, such as spatially-driven operant tasks, described in the following chapter. 


\subsubsection{Spatial operant tasks using the computer screen and a Skinner box}

Rodent spatial cognition is conventionally investigated mainly by tasks in which animals actively move in the environment (e.g. Morris, 1981). Disrupted performance in this case may therefore be caused by deficits in recognizing subject's own position and/or planning and executing goal-directed movements. Attempts have been made to minimize the influence of locomotor components, while extracting recognition components of animal behavior. In experiments by Klement and Bures (2000) rats were passively transported onto a rotating arena through an environment. They were trained to recognize a specific position by reinforcing lever presses at that location. Pastalkova et al. (2003) studied rats watching a rotating scene. These animals were trained to respond when the scene was within a particular sector by reinforcing lever presses while the object was there.

Scientists also developed a behavioral test in which rats observe distant objects on a computer screen, and discriminate their positions by responding to them with a lever press (Nekovarova and Klement, 2006, Klement et al., 2008; Nekovarova et al., 2009; Klement et al., 2010.). Food-deprived rats were placed in a modified Skinner box with an open front wall allowing them to view the screen. The operant chamber was placed in front of a computer screen where the visual stimuli were presented. The rats were trained to press a lever according to these stimuli. The operant responses were rewarded when a particular stimulus or configuration was displayed. We used this experimental apparatus for tasks measuring various types of cognition, i.e., brightness discrimination, object discrimination, and position-discrimination. In the position-discrimination task, rats are trained to press a lever when a stationary object was displayed in a particular position, or when a moving object was passing through a particular region. Animals increased number of responses before the object entered the rewarded area. This suggests these animals recognized the position of the virtual object moving on the computer screen by estimating distance between the object and the rewarded position (Klement et al., 2010).

Other rewarding protocols were also explored in these spatio-operant tests. In other experiments (Nekovarova and Bures, 2006; Nekovarova et. al., 2006), the apparatus consisted of an animal chamber with transparent front wall with four nosing holes organized in the rectangle matrix, arms with water dippers, a water reservoir and a computer monitor. The front wall faced a computer monitor serving to present visual stimuli. The nosing holes in the front wall were equipped by photoelectric devices registering a nose poke in a particular nosing hole. Two dippers (capacity $0.15 \mathrm{ml}$ ) were movable before the front wall. They served to deliver the reward to the animal. They could be raised by electric motors from the water reservoir placed below the box to the level of the particular nosing holes as a result of the animal's correct responses. A transparent sliding barrier, parallel to the front wall, could be closed and prevent access to the nosing holes. The computer registered nose-poking, activated electric motors operating the barrier and the dippers, and displayed graphics on the monitor screen. Initially, water-deprived rats were used and water was presented as a reward. The advantage of this method is the urgency. Rats are highly motivated to respond. However, it is quite difficult to maintain motivation of laboratory animals. Later, a sugar solution was used. Thus, it was not necessary to maintain the rats as water-deprived (which could be quite stressful) and the animals are motivated to respond during the whole day-session. This experimental design was used for the study of higher cognitive functions in rats. We studied their ability to decode abstract 
visual stimuli containing the spatial (configuration) information. Two types of stimuli were presented: 1) Spatial stimuli - They were designed as a simple representation (map) of the real response space (configuration of nosing holes). These stimuli contained configuration information. 2) Non-spatial stimuli - These were simple geometrical patterns without any implicit configuration information. Every picture was connected to a single nosing hole. It was shown that spatial stimuli could be used more effectively than non-spatial stimuli. This experimental apparatus had several advantages. Since exploration is natural behavior for rats, the nose-poking was easier for rats as an operant response than lever-pressing. Another advantage was the opportunity to present wide range of stimuli on the computer screen.

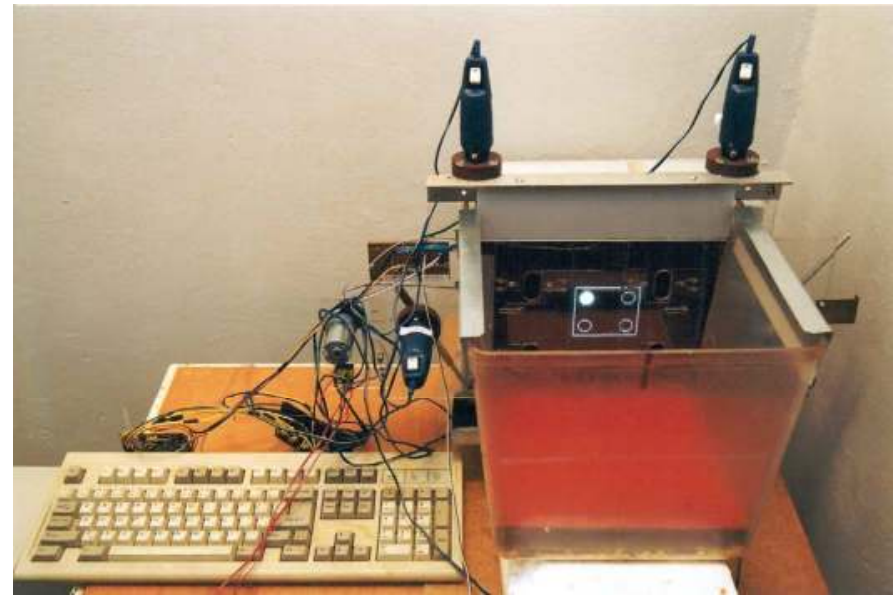

Fig. 2. A photograph of the spatio-operant task designed for studying rats' ability to discriminate position or movement of an object presented on a computer screen. During the test, an animal is placed in the operant box and responds to stimuli projected on the computer monitor with a lever press or nose-poking.

In order to test the usability of this task for pharmacological and animal model research, Levcik examined the effect of systemic injection of MK-801, (RS)-2-chloro-5hydroxyphenylglycine (CHPG, an mGluR5-agonist), and co-administration of both substances on the cognitive performance of rats in this novel spatial task (Levcik et al., 2010). Food-restrained rats were trained to press a lever when an object (white rectangle) moving from one side of the screen to the other was in the particular 'rewarded area'. After the rats had reached the point of asymptotic performance, the effect of MK-801 and CHPG on spatial cognition was tested. Whereas intact rats showed increased frequency before the object entered into the rewarded area, MK-801 $(0.1 \mathrm{mg} / \mathrm{kg}$, i.p.) impaired the ability of animals to recognize the position of the distant objects on the screen, without affecting motor activity. Administration of CHPG $(0.1 \mathrm{mg} / \mathrm{kg}$, i.p.) did not elicit an effect on either the cognitive or motor component of the performance. Treatment with CHPG reduced MK-801-induced impairment of performance of the task, consistent with findings in other laboratories.

These observations suggest that the test provides a novel tool suitable for evaluating disturbances of spatial cognition in animal models of CNS disorders. The major benefit of this novel task, e.g. in comparison with MWM and radial maze, is the ability to dissect 
between cognitive and motor components of animal behavior, which is advantageous particularly in pharmacological research, because many drugs also affect locomotor functions besides learning and cognitive processes. A disadvantage of this method is the relatively long training time compared to other tasks. In operant response to spatial cues rats also tend to use spatial and temporal strategies; rats may use both of them in many versions of these operant tasks. Therefore, it is important to design these tasks in a way that allows a distinction between these strategies. Use of large computer LCD screens provides better control of the shapes of objects, their positions, velocity, and trajectories, as well as the precise timing of experiments. These manipulations may be difficult with physical objects. Moreover, these 'virtual reality' tasks are applicable also to primates and humans (Nekovarova et al., 2009), i.e. they are fully translational. This allows better understanding of the difference in neuronal mechanisms and functions across species, and, thus, better prediction of the ability of novel drugs to ameliorate cognitive impairments in human patients.

\subsubsection{Enemy avoidance task}

The enemy avoidance task in rats was first introduced by Telensky (2009) and the task can be defined as avoidance of a moving conspecific (Telensky et al., 2009) or a mobile object (Telensky et al., 2011). Quite different from the classic avoidance that a rodent would exert facing a real predator or cat odor, the avoidance behavior is reinforced by completely artificial, but well-controlled and reproducible aversive stimulus - electric footshock.

There is an imperceptible zone surrounding the moving stimulus, upon entering the tested subject rat receives a mild footshock and a normal rat eventually learns to avoid such a stimulus with a rapid escape reaction but no signs distress (it still retains foraging for randomly scattered food). It should be kept in mind when interpreting data from this model that it was not designed to reproduce natural defensive behaviors of rats, but developed in the context of the concept of multiple and mutually independent reference frames, such as the dissociated arena and room reference frames in the Carousel maze (see above). In the Carousel maze, two-frame place avoidance and place avoidance tasks in general, brain representations have been studied for coordination function, i.e. segregation and organization of dissociated reference frames (Wesierska et al., 2005, Kubik and Fenton, 2005; Kelemen and Fenton, 2010). An intriguing hypothesis was proposed that such a reference frame could be represented by a moving entity, such as some animal or a thing. The tests were also intended to allow studying physiological substrate of these functions (such as representation of a moving stimulus or even a frame of reference) using lesion, inactivation and electrophysiological measurements. Such an approach was used in the second study, exploiting a moving programmable robot, which showed that avoidance of a moving robot required the hippocampus but avoidance of a stable robot did not.

The first study (Telensky et al., 2009) used a conspecific as the moving object. A laboratory rat (subject) was trained to avoid another rat (enemy), while searching for small pasta pellets dispensed onto an experimental arena. Whenever the distance between the two animals dropped bellow $25 \mathrm{~cm}$, the subject obtained a mild electric footshock. This study showed that rats are capable of avoiding another rat while exploring an environment, suggesting that rat are able to represent moving entities. It should be noted that the learning of this task was relatively slow and required some period of immobilization (with a cage) of the enemy. 
However, the predictability of the enemy rat's movement is obviously slow; moreover rats are known to posses agonistic interactions. The second study (Telensky et al., 2011), thus, used a small mobile robot, which could serve as the center of a to-be-avoided zone in two basic configurations - stable and mobile. In the moving-object configuration, the robot traversed the arena linearly and upon touching the wall it turned a random angle and started to traverse the arena straight again. In the stable-object version, it remained stable and was only moved randomly at longer intervals to prevent place learning. Interestingly, functional inactivation of the dorsal hippocampus with stereotaxic microinjection of teterodotoxin (TTX), sodium channel blocker, which causes cessation of neuronal firing (Zhuravin and Bures, 1991; Klement et al., 2005) disrupted avoidance of the moving but not the stable robot.

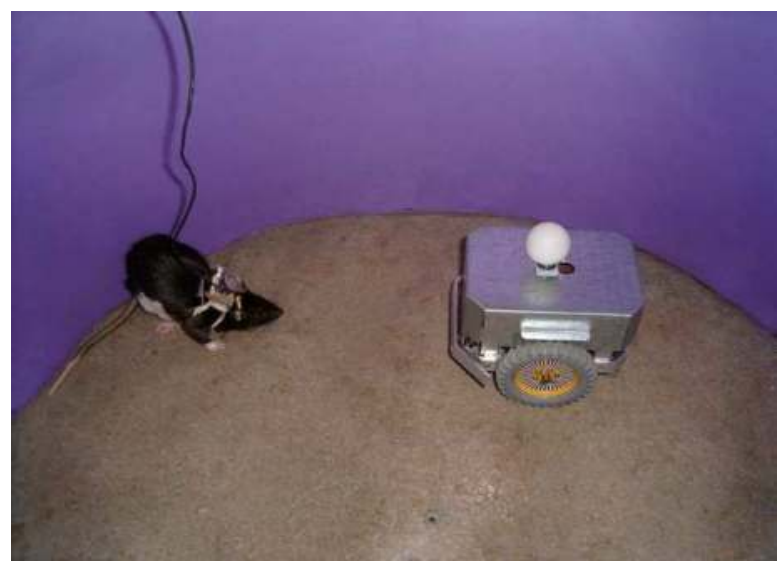

Fig. 3. A laboratory rat solving the Enemy avoidance task. Photograph: Jan Svoboda. Rats foraging for small pasta pellets dropped on the arena floor from an overhead feeder learned to avoid both a stable and randomly moving robot. Nonetheless, navigation with respect to moving robot required an intact hippocampus (Telensky et al., 2011), but avoidance of the stable robot did not. (c) Jan Svoboda

Another interesting test similar to this task but appetitive in nature was proposed in 2008 (Ho et al., 2008), when the authors used a small moving toy car and animals were trained to approach the moving car and this approach was rewarded by intra-cranial stimulation (ICS) (Olds and Milner, 1957; Ho et al., 2008). Activity of hippocampal place-cells was measured. The car-dependent navigation task involved a car inside the arena, and animals obtained a brain reward if it approached and came within $20 \mathrm{~cm}$ of the car. In car-independent navigation, the rats were rewarded for traveling $150 \mathrm{~cm}$ regardless of relation to the car. Place fields were remapped more frequently in the car-dependent than car-independent tasks. Place cell activity in both conditions showed moderate tuning to the movement parameters of the rats and car, and the distance between the car and rats. Place-cell tuning to the movement variables of the car was more specific in the version with the car than without the car. The coding of movement variables of the car by the place-cell activity was larger in the cardependent than car-independent task. This intriguing study showed that activity of hippocampal place cells may represent not only an animal's own location but also the movement parameters of another moving object if it is associated with a reward. The study 
also suggests a neural correlate of representation of a moving object in the activity of place cells localized to the hippocampus. The recent study (Telensky et al., 2011) supports findings of the study by $\mathrm{Ho}$ et al. and these findings showed the requirement of functional hippocampal integrity for such a representation of a moving object, defined here in the aversive terms. These results also seem to extend Cognitive Map Theory of the hippocampus function (O'Keefe and Nadel, 1978) showing that visibility is not the sole decisive factor for hippocampus-dependence of the task and that stability and/or motion of object must be considered as well. This view has a close analogy with a proposed role of hippocampus in the 'automatic recording of attended experience' (Morris and Frey, 1997). Continuous updating of the dynamically changing position of a moving object may thus represent such a phenomenon. Studies aimed at these abilities are required for pre-clinical research, because in many brain disorders, such information flow and working memory capabilities strongly decline, such as in psychoses or dementias. However, it must be noted that the translational potential of the test is yet unexplored. For use in humans the test has to be made appetitive and simplified to provide easy administration and evaluation. This is in the plans of our laboratory.

\section{Conclusion}

Pre-clinical research into animal models of CNS disorders require appropriate behavioral tests for detection of outcomes of brain manipulation pursued in the model. This work has surveyed some of the classically used tests such as radial or Morris water mazes and introduced several novel tests, which have the potential to be used in animal model research due to the specific functions they examine (place navigation, cognitive coordination, continuous updating of position of a moving stimulus). Application of these tasks in the research of animal models of CNS disorders and accompanying cognitive and information-processing deficits is still a work in progress. Experiments are being performed with moving stimuli in animal models of cognitive deficit and in animal models of schizophrenia-like behaviors induced by low dose MK-801, a high-affinity non-competitive NMDA receptor antagonist. The hippocampus requirement of these tasks (Wesierska et al., 2005; Kubik and Fenton, 2005, Telensky et al., 2011) and their aim at spatial navigation (as a model of declarative memory) and other higher cognitive functions (impaired in many neuropsychiatric diseases) suggest that they might become a powerful tool in pre-clinical research oriented toward animal models and the discovery of drugs aimed at cognitive functions.

\section{Acknowledgment}

The authors express gratitude to Dr. Jan Bures for critical opinions and scientific inspiration. Thanks belong also to Peter M. Luketic for the language review of the draft and to all members of the laboratory for their support. This study was supported by GACR grants P303/10/J032 and 309/09/0286, GACR Center of Excellence P304/12/G069 and by AV0Z50110509. All authors were also supported by AV0Z50110509

\section{References}

Abdel Baki, S.G., Kao, H.Y., Kelemen, E., Fenton, A.A., Bergold, P.J. (2009). A hierarchy of neurobehavioral tasks discriminates between mild and moderate brain injury in rats. Brain Research, Vol. 1280, pp. 98-106, ISSN 0006-8993 
Adler, L.E., Pachtman, E., Franks, R.D., Pecevich, M., Waldo, M.C., Freedman, R. (1982). Neurophysiological evidence for a defect in neuronal mechanisms involved in sensory gating in schizophrenia. Biological Psychiatry. Vol. 17, No. 6, pp. 639-654, ISSN 0006-3223

Adler, L.E., Rose, G., Freedman, R. (1986). Neurophysiological studies of sensory gating in rats: effects of amphetamine, phencyclidine, and haloperidol. Biological Psychiatry. Vol. 21, No. 8-9, pp. 787-98, ISSN 0006-3223

Ammassari-Teule, M., Caprioli, A. (1985). Spatial learning and memory, maze running strategies and cholinergic mechanisms in two inbred strains of mice. Behavioral Brain Research, Vol.17, No. 1, pp. 9-16, ISSN 0166-4328

Arnt, J., Skarsfeldt, T., Hyttel, J. (1997). Differentiation of classical and novel antipsychotics using animal models. International Clinical Psychopharmacology, Vol. 12, Suppl 1, pp. S9-S17, ISSN 1473-5857

Auclair, A.L., Kleven, M.S., Besnard, J., Depoortère, R., Newman-Tancredi, A. (2006). Actions of novel antipsychotic agents on apomorphine-induced PPI disruption: influence of combined serotonin 5-HT1A receptor activation and dopamine D2 receptor blockade. Neuropsychopharmacology „, Vol. 31, No. 9, pp. 1900-1909, ISSN 0893-133X

Baker, N.J., Staunton, M., Adler, L.E., Gerhardt, G.A., Drebing, C., Waldo, M., Nagamoto, H., Freedman, R. (1990). Sensory gating deficits in psychiatric inpatients: relation to catecholamine metabolites in different diagnostic groups. Biological Psychiatry, Vol. 27, No. 5, pp.519-528, ISSN 0006-3223

Bakshi, V.P., Swerdlow, N.R., Braff, D.L., Geyer, M.A. (1998). Reversal of isolation rearinginduced deficits in prepulse inhibition by Seroquel and olanzapine. Biological Psychiatry. Vol. 43, No. 6, pp. 436-445, ISSN 0006-3223

Beiko, J., Candusso, L., Cain, D.P. (1997). The effect of nonspatial water maze pretraining in rats subjected to serotonin depletion and muscarinic receptor antagonism: a detailed behavioural assessment of spatial performance. Behavioral Brain Research, Vol. 88, No. 2, pp. 201-211, ISSN 0166-4328

Benhamou, S. (1997). Path integration by swimming rats. Animal Behaviour, Vol. 54, No. 2, pp. 321-327, ISSN: 0003-3472

Blahna, K., Svoboda, J., Telensky, P., Klement, D. (2011). Inertial stimuli generated by arena rotation are important for acquisition of the active place avoidance task. Behavioral Brain Research, Vol. 216, No. 1, pp. 207-213, ISSN 0166-4328

Bolhuis, J.J., Bijlsma, S., Ansmink, P. (1986). Exponential decay of spatial memory of rats in a radial maze. Behavioral and Neural Biology, Vol. 46, No. 2, pp. 115-122, ISSN 01631047

Braff, D.L., Geyer, M.A. (1990). Sensorimotor gating and schizophrenia. Human and animal model studies. Archives of General Psychiatry, Vol. 47, No. 2, pp. 181-188, ISSN 0003-990x

Braff, D.L., Grillon, C., Geyer, M.A. (1992). Gating and habituation of the startle reflex in schizophrenic patients. Archives of General Psychiatry, Vol. 49, No. 3, pp. 206-215, ISSN 0003-990x

Broadbent, N.J., Squire, L.R., Clark, R.E. (2006). Reversible hippocampal lesions disrupt water maze performance during both recent and remote memory tests. Learning and Memory, Vol. 13, pp. 187-191, ISSN 1072-0502 
Bubeníková, V., Votava, M., Horácek, J., Pálenícek, T. (2005a). Relation of sex and estrous phase to deficits in prepulse inhibition of the startle response induced by ecstasy (MDMA). Behavioural Pharmacology, Vol. 16, No. 2, pp. 127-130, ISSN 0955-8810

Bubeníková, V., Votava, M., Horácek, J., Pálenícek, T., Dockery, C. (2005b). The effect of zotepine, risperidone, clozapine and olanzapine on MK-801-disrupted sensorimotor gating. Pharmacology, Biochemistry and Behavior, Vol. 80, No. 4, pp. 591-596, ISSN 0091-3057

Bubeníková-Valesová, V., Votava, M., Pálenícek, T., Horácek, J. (2007). The opposite effect of a low and a high dose of serotonin-1A agonist on behavior induced by MK-801. Neuropharmacology, Vol. 52, No. 4, pp. 1071-1078, ISSN 0028-3908

Bubenikova-Valesova, V., Stuchlik, A., Svoboda, J., Bures, J., Vales, K. (2008a). Risperidone and ritanserin but not haloperidol block effect of dizocilpine on the active allothetic place avoidance task. Proceedings of the National Academy of Sciences, USA, Vol. 105, No. 3, pp. 1061-1066, ISSN 0027-8424

Bubeníková-Valesová, V., Horácek, J., Vrajová, M., Höschl, C. (2008b). Models of schizophrenia in humans and animals based on inhibition of NMDA receptors. Neuroscience and Biobehavioral Reviews, Vol. 32, No. 5, pp. 1014-1023, ISSN 01497634

Bures, J., Fenton, A.A., Kaminsky, Y., Zinyuk, L. (1997). Place cells and place navigation. Proceedings of the National Academy of Sciences, USA, Vol. 94, No. 1, pp. 343-350, ISSN 0027-8424

Bures, J., Fenton, A.A., Kaminsky, Y., Wesierska, M., Zahalka, A. (1998). Rodent navigation after dissociation of the allocentric and idiothetic representations of space. Neuropharmacology, Vol.37, No. 4-5, pp. 689-699,

Buresová, O., Bures, J. (1982). Radial maze as a tool for assessing the effect of drugs on the working memory of rats. Psychopharmacology, Vol. 77, No. 3, pp. 268-271, ISSN 0033-3158

Buresová, O., Bures, J., Oitzl, M.S., Zahálka, A. (1985a). Radial maze in the water tank: an aversively motivated spatial working memory task. Physiology and Behavior, Vol. 34, No. 6, pp. 1003-1005, ISSN 0031-9384

Buresová, O., Krekule, I., Zahálka, A., Bures, J. (1985b). On-demand platform improves accuracy of the Morris water maze procedure. Journal of Neuroscience Methods, Vol. 15, No. 1, pp. 63-72, ISSN 0165-0270

Cain, D.P., Saucier, D., Boon, F. (1997a). Testing hypotheses of spatial learning: the role of NMDA receptors and NMDA-mediated long-term potentiation. Behavioral Brain Research, Vol. 84, No. 1-2, pp. 179-193, ISSN 0166-4328

Cain, D.P. (1997b). Prior non-spatial pretraining eliminates sensorimotor disturbances and impairments in water maze learning caused by diazepam. Psychopharmacology, Vol. 130, No. 4, pp. 313-319, ISSN 0033-3158

Castagné, V., Moser, P.C., Porsolt, R.D. (2009). Preclinical behavioral models for predicting antipsychotic activity. Advances in Pharmacology, Vol. 57, pp. 381-418, ISSN 10543589

Castellanos, F.X., Fine, E.J., Kaysen, D., Marsh, W.L., Rapoport, J.L., Hallett, M. (1996). Sensorimotor gating in boys with Tourette's syndrome and ADHD: preliminary results. Biological Psychiatry, Vol. 39, No. 1, pp. 33-41, ISSN 0006-3223 
Cimadevilla, J.M., Kaminsky, Y., Fenton, A., Bures, J. (2000a). Passive and active place avoidance as a tool of spatial memory research in rats. Journal of Neuroscience Methods, Vol. 102, No. 2, pp. 155-164, ISSN 0165-0270

Cimadevilla, J.M., Fenton, A.A., Bures, J. (2000b). Continuous place avoidance task reveals differences in spatial navigation in male and female rats. Behavioral Brain Research, Vol. 107, No. 1-2, pp. 161-169, ISSN 0166-4328

Cimadevilla, J.M., Fenton, A.A., Bures, J. (2000c). Functional inactivation of dorsal hippocampus impairs active place avoidance in rats. Neuroscience Letters, Vol. 285, No. 1, pp. 53-56, ISSN 0304-3940

Cimadevilla, J.M., Fenton, A.A., Bures, J. (2001a). New spatial cognition tests for mice: passive place avoidance on stable and active place avoidance on rotating arenas. Brain Research Bulletin, Vol. 54, No. 5, pp. 559-563, ISSN: 0361-9230

Cimadevilla, J.M., Fenton, A.A., Bures, J. (2001b). Transient sex differences in the betweensessions but not in the within-session memory underlying an active place avoidance task in weanling rats. Behavioral Neuroscience, Vol. 115, No. 3, pp. 695703, ISSN 0735-7044

Cimadevilla, J.M., Wesierska, M., Fenton, A.A., Bures, J. (2001c). Inactivating one hippocampus impairs avoidance of a stable room-defined place during dissociation of arena cues from room cues by rotation of the arena. Proceedings of the National Academy of Sciences, USA, Vol. 98, No. 6, pp. 3531-3536, ISSN 0027-8424

Clark, R.E., Martin, S.J. (2005a). Interrogating rodents regarding their object and spatial memory. Current Opinion in Neurobiology, Vol. 15, No. 5, pp. 593-598, ISSN 09594388

Clark, R.E., Broadbent, N.J., Squire, L.R. (2005b). Hippocampus and remote spatial memory in rats. Hippocampus, Vol. 15, pp. 260-272, ISSN 1050-9631

Conzelmann, A., Pauli, P., Mucha, R.F., Jacob, C.P., Gerdes, A.B., Romanos, J., Bähne, C.G., Heine, M., Boreatti-Hümmer, A., Alpers, G.W., Fallgatter, A.J., Warnke, A., Lesch, K.P., Weyers, P. (2010). Early attentional deficits in an attention-to-prepulse paradigm in ADHD adults. J Abnorm Psychol. Vol. 119, No. 3, pp. 594-603, ISSN 1050-9631

Cook, R.G., Brown, M.F., Riley, D.A. (1985). Flexible memory processing by rats: use of prospective and retrospective information in the radial maze. Journal of Experimental Psychology: Animal Behavior Processes, Vol. 11, No. 3, pp. 453-469, ISSN 0097-7403

de Bruin, N.M., Ellenbroek, B.A., Cools, A.R., Coenen, A.M., van Luijtelaar, E.L. (1999). Differential effects of ketamine on gating of auditory evoked potentials and prepulse inhibition in rats. Psychopharmacology, Vol. 142, No. 1, pp. 9-17, ISSN 0033-3158

D'Hooge, R., De Deyn, P.P. (2001). Applications of the Morris water maze in the study of learning and memory. Brain Research Reviews, Vol. 36, No. 1, pp. 60-90, ISSN 01650173

Dockery, C.A., Wesierska, M.J. (2010). A spatial paradigm, the allothetic place avoidance alternation task, for testing visuospatial working memory and skill learning in rats. Journal of Neuroscience Methods, Vol. 191, No. 2, pp. 215-221, ISSN 0165-0270 
Dubreuil, D., Tixier, C., Dutrieux, G., Edeline, J.M. (2003). Does the radial arm maze necessarily test spatial memory? Neurobiology of Learning and Memory, Vol. 79, No. 1, pp. 109-117, ISSN 1074-7427

Dudchenko, P.A. (2004). An overview of the tasks used to test working memory in rodents. Neuroscience and Biobehavioral Reviews, Vol. 28, No. 7, pp. 699-709,

Dvorkin, A., Culver, K.E., Waxman, D., Szechtman, H., Kolb, B. (2008). Effects of hypophysectomy on compulsive checking and cortical dendrites in an animal model of obsessive-compulsive disorder. Behavioural Pharmacology, Vol. 19, No. 4, pp. 271-283, ISSN 0955-8810

Dvorkin, A., Silva, C., McMurran, T., Bisnaire, L., Foster, J., Szechtman, H. (2010). Features of compulsive checking behavior mediated by nucleus accumbens and orbital frontal cortex. European Journal of Neuroscience, Vol. 32, No. 9, pp. 1552-1563, online ISSN 1460-9568

Ellenbroek, B.A., Cools, A.R. (1990). Animal models with construct validity for schizophrenia. Behavioural Pharmacology, Vol. 1, No. 6, pp. 469-490, ISSN 09558810

Ellenbroek, B.A., van den Kroonenberg, P.T., Cools, A.R. (1998). The effects of an early stressful life event on sensorimotor gating in adult rats. Schizophrenia Research, Vol. 30, No. 3, pp. 251-260, ISSN 0920-9964

Ellenbroek, B.A., Cools, A.R. (2000). The long-term effects of maternal deprivation depend on the genetic background. Neuropsychopharmacology,, Vol. 23, No. 1, pp. 99-106, ISSN 0893-133X

Fenton, A.A., Wesierska, M., Kaminsky, Y., Bures, J. (1998). Both here and there: simultaneous expression of autonomous spatial memories in rats. Proceedings of the National Academy of Sciences, USA, Vol. 95, No. 19, pp. 11493-11498, ISSN 0027-8424

Franks, R.D., Adler, L.E., Waldo, M.C., Alpert, J., Freedman, R. (1983). Neurophysiological studies of sensory gating in mania: comparison with schizophrenia. Biological Psychiatry, Vol. 18, No. 9, pp. 989-1005, ISSN 0006-3223

Garthe, A., Behr, J., Kempermann, G. (2009). Adult-generated hippocampal neurons allow the flexible use of spatially precise learning strategies. PLoS ONE, Vol. 4, No. 5, pp. e5464, EISSN 1932-6203

Geyer, M.A., Wilkinson, L.S., Humby, T., Robbins, T.W. (1993). Isolation rearing of rats produces a deficit in prepulse inhibition of acoustic startle similar to that in schizophrenia. Biological Psychiatry, Vol. 34, No. 6, pp. 361-372, ISSN 0006-3223

Geyer, M.A., McIlwain, K.L., Paylor, R.(2002). Mouse genetic models for prepulse inhibition: an early review. Molecular Psychiatry, Vol. 7, No. 10, pp. 1039-1053, ISSN 13594184

Geyer, M.A. (2008). Developing translational animal models for symptoms of schizophrenia or bipolar mania. Neurotoxicity Research, Vol. 14, No. 1, pp. 71-78, ISSN 1029-8428

Giakoumaki, S.G., Roussos, P., Rogdaki, M., Karli, C., Bitsios, P., Frangou, S. (2007). Evidence of disrupted prepulse inhibition in unaffected siblings of bipolar disorder patients. Biological Psychiatry, Vol. 62, No. 12, pp. 1418-1422, ISSN 0006-3223

Hafting, T., Fyhn, M., Molden, S., Moser, M.B., Moser, EI. (2005). Microstructure of a spatial map in the entorhinal cortex. Nature, Vol. 436, No. 7052, pp. 801-806, ISSN 00280836 
Hejl, A.M., Glenthøj, B., Mackeprang, T., Hemmingsen, R., Waldemar, G. (2004). Prepulse inhibition in patients with Alzheimer's disease. Neurobiology of Aging, Vol. 25, No. 8, pp. 1045-1050, ISSN 0197-4580

Ho, S.A., Hori, E., Kobayashi, T., Umeno, K., Tran, A.H., Ono, T., Nishijo, H.(2008). Hippocampal place cell activity during chasing of a moving object associated with reward in rats. Neuroscience, Vol. 157, No. 1, pp. 254-270, ISSN 0306-4522

Hoenig, K., Hochrein, A., Quednow, B.B., Maier, W., Wagner, M. (2005). Impaired prepulse inhibition of acoustic startle in obsessive-compulsive disorder. Biological Psychiatry, Vol. 57, No. 10, pp. 1153-1158, ISSN 0006-3223

Hok, V., Save, E., Lenck-Santini, P.P., Poucet, B. (2005). Coding for spatial goals in the prelimbic/infralimbic area of the rat frontal cortex. Proceedings of the National Academy of Sciences, USA, Vol. 102, No. 12, pp. 4602-4607, ISSN 0027-8424

Hok, V., Lenck-Santini, P.P., Roux, S., Save, E., Muller, R.U., Poucet, B. (2007). Goal-related activity in hippocampal place cells. Journal of Neuroscience, Vol. 27, No. 3, pp. $472-$ 482, ISSN 0270-6474

Hölscher, C. (1999). Stress impairs performance in spatial water maze learning tasks. Behavioral Brain Research, Vol. 100, No. 1-2, pp. 225-235, ISSN 0166-4328

Hort, J., Laczó, J., Vyhnálek, M., Bojar, M., Bures, J., Vlcek, K. (2007). Spatial navigation deficit in amnestic mild cognitive impairment. Proceedings of the National Academy of Sciences, USA, Vol. 104, No. 10, pp. 4042-4047, ISSN 0027-8424

Jones, C.K., Shannon, H.E. (2000). Muscarinic cholinergic modulation of prepulse inhibition of the acoustic startle reflex. Journal of Pharmacology and Experimental Therapeutics, Vol. 294, No. 3, pp. 1017-1023, ISSN 0022-3565

Keeler, J.F., Robbins, T.W. (2011). Translating cognition from animals to humans. Biochemical Pharmacology, Vol. 81, No. 12, pp. 1356-1366,

Kelemen, E., Fenton, A.A. (2010). Dynamic grouping of hippocampal neural activity during cognitive control of two spatial frames. PLoS Biology, Vol. 8, No. 6, pp. e1000403, ISSN-1544-9173

Klement, D., Bures, J. (2000). Place recognition monitored by location-driven operant responding during passive transport of the rat over a circular trajectory. Proceedings of the National Academy of Sciences, USA, Vol. 97, No. 6, pp. 29462951, ISSN 0027-8424

Klement D, Past'alková E, Fenton AA. (2005). Tetrodotoxin infusions into the dorsal hippocampus block non-locomotor place recognition. Hippocampus, Vol. 15, No. 4, pp. 460-471, ISSN 1050-9631

Klement, D., Blahna, K., Nekovárová, T. (2008). Novel behavioral tasks for studying spatial cognition in rats. Physiological Research, Vol.57, Suppl 3, pp. S161-S165, ISSN 08628408

Klement, D., Levcik, D., Duskova, L., Nekovarova, T. (2010). Spatial task for rats testing position recognition of an object displayed on a computer screen. Behavioral Brain Research, Vol. 207, No. 2, pp. 480-489, ISSN 0166-4328

Kubík, S., Fenton, A.A. (2005). Behavioral evidence that segregation and representation are dissociable hippocampal functions. Journal of Neuroscience, Vol. 25, No. 40, pp. 9205-9212, ISSN 0270-6474 
Kubík, S., Stuchlík, A., Fenton, A.A. (2006). Evidence for hippocampal role in place avoidance other than merely memory storage. Physiological Research, Vol. 55, No. 4, pp. 445-452, ISSN 0862-8408

Kubik, S., Miyashita, T., Guzowski, J.F. (2007). Using immediate-early genes to map hippocampal subregional functions. Learning and Memory, Vol. 14, No. 11. pp. 758-770, ISSN 1072-0502

Le Pen, G., Moreau, J.L. (2002). Disruption of prepulse inhibition of startle reflex in a neurodevelopmental model of schizophrenia: reversal by clozapine, olanzapine and risperidone but not by haloperidol. Neuropsychopharmacology, Vol. 27, No. 1, pp. 1-11, ISSN 0028-3908

Levcik, D., Klement, D., Vales, K., Nekovarova, T., Stuchlik, A. (2010). Antagonist of NMDA receptors MK-801 disrupts recognition of the position of a distant object. Psychiatrie, Vol. 14, No. 2, pp. 15-18, ISSN 1211-7579

Lever, C., Burton, S., Jeewajee, A., O'Keefe, J., Burgess, N. (2009). Boundary vector cells in the subiculum of the hippocampal formation. Journal of Neuroscience, Vol. 29, No. 31, pp. 9771-9777, ISSN 0270-6474

Maguire, E.A., Nannery, R., Spiers, H.J. (2006). Navigation around London by a taxi driver with bilateral hippocampal lesions. Brain, Vol. 129, No. Pt 11, pp. 2894-2907, ISSN 0006-8950

Mansbach, R.S., Geyer, M.A., Braff, D.L. (1988). Dopaminergic stimulation disrupts sensorimotor gating in the rat. Psychopharmacology, Vol. 94, No. 4, pp. 507-514, ISSN 0033-3158

Mansbach, R.S., Geyer, M.A. (1989). Effects of phencyclidine and phencyclidine biologs on sensorimotor gating in the rat. Neuropsychopharmacology, Vol. 2, No. 4, pp.299308, ISSN 0893-133X

Markowska, A.L., Long, J.M., Johnson, C.T., Olton, D.S. (1993). Variable-interval probe test as a tool for repeated measurements of spatial memory in the water maze. Behavioral Neuroscience. Vol. 107, No. 4, pp. 627-632, ISSN 0735-7044

Martin, L.F., Kem, W.R., Freedman, R. (2004). Alpha-7 nicotinic receptor agonists: potential new candidates for the treatment of schizophrenia. Psychopharmacology, Vol. 174, No. 1, pp. 54-64, ISSN 0033-3158

Martin, S.J., de Hoz, L., Morris, R.G. (2005). Retrograde amnesia: Neither partial nor complete hippocampal lesions in rats result in preferential sparing of remote spatial memory, even after reminding. Neuropsychologia, Vol. 43, pp. 609-624, ISSN 00283932

Martin, L.F., Freedman, R. (2007). Schizophrenia and the alpha7 nicotinic acetylcholine receptor. International Review of Neurobiology, Vol. 78, pp. 225-246, ISSN 00747742

McNamara, R.K., Skelton, R.W. (1993). The neuropharmacological and neurochemical basis of place learning in the Morris water maze. Brain Research Reviews, Vol. 18, No. 1, pp. :33-49 - ISSN 0165-0173

Mittelstaedt, M.L., Mittelstaedt, H. (1980). Homing by path integration in a mammal. Naturwissenschaften, Vol. 67, pp. 566-567, ISSN 0028-1042

Mittelstaedt, M.L., Glasauer, S. (1991). Idiothetic navigation in gerbils and humans. Zoologische Jahrbücher. Abteilung für allgemeine Zoologie und Physiologie der Tiere, pp. 427-435, ISSN 0044-5185 
Moghaddam, M., Bures, J. (1996). Contribution of egocentric spatial memory to place navigation of rats in the Morris water maze. Behavioral Brain Research, Vol. 78, No. 2, pp. 121-129, ISSN 0166-4328

Moghaddam, M., Bures, J. (1997). Rotation of water in the Morris water maze interferes with path integration mechanisms of place navigation. Neurobiology of Learning and Memory, Vol. 68, No. 3, pp. 239-251, ISSN 1074-7427

Morris, R.G.M. (1981). Spatial localization does not require the presence of local cues, Learning and Motivation, Vol. 12, pp. 239-260, ISSN 0023-9690

Morris, R.G.M., Garrud, P., Rawlings, J. and O'Keefe, J. (1982). Place navigation impaired in rats with hippocampal lesions. Nature, Vol. 297, pp. 681-683, ISSN 0028-0836

Morris, R., (1984). Developments of a water-maze procedure for studying spatial learning in the rat, Journal of Neuroscience Methods, Vol. 11, pp. 47-60, ISSN 0165-0270

Morris, R.G., Frey, U. (1997). Hippocampal synaptic plasticity: role in spatial learning or the automatic recording of attended experience? Philosophical Transactions of the Royal Society of London Series B, Vol. 352, No. 1360, pp. 1489-1503, ISSN 0080-4622

Muller, R. (1996). A quarter of a century of place cells. Neuron, Vol. 17, No. 5, pp. 813-822, ISSN 0896-6273

Nekovarova, T., Bures, J. (2006a). Spatial decisions in rats based on the geometry of computer-generated patterns. Neuroscience Letters, Vol. 394, No. 3, pp. 211-215, ISSN 0304-3940

Nekovárová, T., Klement, D. (2006b). Operant behavior of the rat can be controlled by the configuration of objects in an animated scene displayed on a computer screen. Physiological Research, Vol. 55, No. 1, pp. 105-113, ISSN 0862-8408

Nekovarova, T., Nedvidek, J., Bures, J. (2006c). Spatial choices of rats based on abstract visual information: Pattern- or configuration-discrimination? Behavioral Brain Research, Vol. 172, No. 2, pp. 264-271, ISSN 0166-4328

Nekovarova, T., Nedvidek, J., Klement, D., Bures, J. (2009). Spatial decisions and cognitive strategies of monkeys and humans based on abstract spatial stimuli in rotation test. Proceedings of the National Academy of Sciences, USA, Vol. 106, No. 36, pp. 1547815482, ISSN 0027-8424

O'Carroll, C.M., Martin, S.J., Sandin, J., Frenguelli, B., Morris, R.G. (2006). Dopaminergic modulation of the persistence of one-trial hippocampus-dependent memory. Learning and Memory, Vol. 13, No. 6, pp. 760-769, ISSN 1072-0502

O'Keefe, J. Dostrovsky, J. (1971). The hippocampus as a spatial map. Preliminary evidence from unit activity in the freely moving rat. Brain Research, Vol. 34, pp. 171-175, ISSN 0006-8993

O'Keefe, J., Nadel, L. (1978). The Hippocampus as a Cognitive Map. Clarendon Press, ISBN 0-19-857206-9

Olds, J., Milner, P. (1954). Positive reinforcement produced by by electrical stimulation of septal area. Journal of Comparative \& Physiological Psychology, Vol. 47, pp. 419427, ISSN 0021-9940

Olton, D.S., Samuelson, R.J. (1976). Remembrance of places passed: spatial memory in rats, Journal of Experimental Psychology: Animal Behavior Processes, Vol. 2, pp. 97-116, ISSN 0097-7403

Olton, D.S., Paras, B.C. (1979a). Spatial memory and hippocampal function. Neuropsychologia, Vol. 17, No. 6, pp. 669-682, ISSN 0028-3932 
Olton, D.S. (1979b). Mazes, maps, and memory. American Psychologist, Vol. 34, No. 7, pp. 583-596, ISSN 0003-066X

Olton, D.S., Becker, J.T., Handelmann, G.E. (1980). Hippocampal function - working memory or cognitive mapping. Physiological psychology, Vol. 8, No. 2, pp. 239,

Ouagazzal, A., Grottick, A.J., Moreau, J., Higgins, G.A. (2001). Effect of LSD on prepulse inhibition and spontaneous behavior in the rat. A pharmacological analysis and comparison between two rat strains. Neuropsychopharmacology, Vol. 25, No. 4, pp. 565-575, ISSN 0893-133X

Packard, M.G., Hirsh, R., White, N.M. (1989). Differential effects of fornix and caudate nucleus lesions on two radial maze tasks: evidence for multiple memory systems. Journal of Neuroscience, Vol. 9, No. 5, pp. 1465-1472, ISSN 0270-6474

Pálenícek, T., Hlinák, Z., Bubeníková-Valesová, V., Votava, M., Horácek, J. (2007). An analysis of spontaneous behavior following acute MDMA treatment in male and female rats. Neuroendocrinology Letters, Vol. 28, No. 6, pp. 781-788, ISSN 0172$780 \mathrm{X}$

Pálenícek, T., Balíková, M., Bubeníková-Valesová, V., Horácek, J. (2008). Mescaline effects on rat behavior and its time profile in serum and brain tissue after a single subcutaneous dose. Psychopharmacology, Vol. 196, No. 1, pp. 51-62, ISSN 00333158

Pastalkova, E., Kelemen, E., Bures, J. (2003). Operant behavior can be triggered by the position of the rat relative to objects rotating on an inaccessible platform. Proceedings of the National Academy of Sciences, USA, Vol. 100, No. 4, pp. 20942099, ISSN 0027-8424

Pastalkova, E., Serrano, P., Pinkhasova, D., Wallace, E., Fenton, A.A., Sacktor, T.C. (2006). Storage of spatial information by the maintenance mechanism of LTP. Science. Vol. 313, No. 5790, pp. 1141-1144, ISSN 0036-8075

Powell, S.B., Zhou, X., Geyer, M.A. (2009). Prepulse inhibition and genetic mouse models of schizophrenia. Behavioral Brain Research, Vol. 204, No. 2, pp. 282-294, ISSN 01664328

Rambousek, L., Bubenikova-Valesova, V., Kacer, P., Syslova, K., Kenney, J., Holubova, K., Najmanova, V., Zach, P., Svoboda, J., Stuchlik, A., Chodounska, H., Kapras, V., Adamusova, E., Borovska, J., Vyklicky, L., Vales, K. (2011). Cellular and behavioural effects of a new steroidal inhibitor of the N-methyl-d-aspartate receptor 3a5 $\beta$-pregnanolone glutamate. Neuropharmacology, Vol. 61, No. 1-2, pp. 61-6, ISSN 0028-3908

Rezacova, L., Svoboda, J., Stuchlik, A., Vales, K. (2011). Differential effects of stable elevated levels of corticotropin-releasing hormone and systemic corticosterone on various types of rat learning. Neuroendocrinology Letters, Vol. 32, No. 1, pp. 64-76, ISSN 0172-780X

Rich, B.A., Vinton, D., Grillon, C., Bhangoo, R.K., Leibenluft, E. (2005). An investigation of prepulse inhibition in pediatric bipolar disorder. Bipolar Disorders, Vol. 7, No. 2, pp. 198-203, ISSN 1398-5647

Sams-Dodd, F., Lipska, B.K., Weinberger, D.R. (1997). Neonatal lesions of the rat ventral hippocampus result in hyperlocomotion and deficits in social behaviour in adulthood. Psychopharmacology, Vol. 132, No. 3, pp. 303-310, ISSN 0033-3158 
Saucier, D., Hargreaves, E.L., Boon, F., Vanderwolf, C.H., Cain, D.P. (1996). Detailed behavioral analysis of water maze acquisition under systemic NMDA or muscarinic antagonism: nonspatial pretraining eliminates spatial learning deficits. Behavioral Neuroscience, Vol. 110, No. 1, pp. 103-116, ISSN 0735-7044

Sharma, S., Rakoczy, S., Brown-Borg, H. (2010). Assessment of spatial memory in mice. Life Science, Vol. 87, No. 17-18, pp. 521-536, ISSN 0024-3205

Skarsfeldt, T. (1996). Differential effect of antipsychotics on place navigation of rats in the Morris water maze. A comparative study between novel and reference antipsychotics. Psychopharmacology, Vol. 124, No. 1-2, pp. 126-133, ISSN 0033-3158

Solstad, T., Boccara, C.N., Kropff, E., Moser, M.B., Moser, E.I. (2008). Representation of geometric borders in the entorhinal cortex. Science, Vol. 322, No. 5909, pp. 18651868, ISSN 0036-8075

Spooner, R.I., Thomson, A., Hall, J., Morris, R.G., Salter, S.H. (1994). The Atlantis platform: a new design and further developments of Buresova's on-demand platform for the water maze. Learning and Memory, Vol. 1, No. 3, pp. 203-211, ISSN 1072-0502

Steele, R.J., Morris, R.G. (1999). Delay-dependent impairment of a matching-to-place task with chronic and intrahippocampal infusion of the NMDA-antagonist D-AP5. Hippocampus, Vol. 9, No. 2, pp. 118-136, ISSN 1050-9631

Stuchlik, A., Fenton, A.A., Bures, J. (2001). Substratal idiothetic navigation of rats is impaired by removal or devaluation of extramaze and intramaze cues. Proceedings of the National Academy of Sciences, USA, Vol. 98, No. 6, pp. 3537-3542, ISSN 0027-8424

Stuchlik, A., Bures, J. (2002). Relative contribution of allothetic and idiothetic navigation to place avoidance on stable and rotating arenas in darkness. Behavioral Brain Research, Vol. 128, No. 2, pp. 179-188, ISSN 0166-4328

Stuchlik, A., Rezacova, L., Vales, K., Bubenikova, V., Kubik, S. (2004). Application of a novel Active Allothetic Place Avoidance task (AAPA) in testing a pharmacological model of psychosis in rats: comparison with the Morris Water Maze. Neuroscience Letters, Vol. 366, No. 2, pp. 162-166, ISSN 0304-3940

Stuchlík, A., Vales, K. (2005). Systemic administration of MK-801, a non-competitive NMDA-receptor antagonist, elicits a behavioural deficit of rats in the Active Allothetic Place Avoidance (AAPA) task irrespectively of their intact spatial pretraining. Behavioral Brain Research, Vol. 159, No. 1, pp. 163-171, ISSN 0166-4328

Stuchlik, A., Rehakova, L., Telensky, P., Vales, K. (2007a). Morris water maze learning in Long-Evans rats is differentially affected by blockade of D1-like and D2-like dopamine receptors. Neuroscience Letters, Vol. 422, No. 3, pp. 169-174, ISSN 03043940

Stuchlik, A., Rehakova, L., Rambousek, L., Svoboda, J., Vales, K. (2007b). Manipulation of D2 receptors with quinpirole and sulpiride affects locomotor activity before spatial behavior of rats in an active place avoidance task. Neuroscience Research, Vol. 58, No. 2, pp. 133-139, ISSN 0168-0102

Stuchlík, A., Petrásek, T., Vales, K. (2009). Effect of alpha(1)-adrenergic antagonist prazosin on behavioral alterations induced by MK-801 in a spatial memory task in LongEvans rats. Physiological Research, Vol. 58, No. 5, pp. 733-740, ISSN 0862-8408

Stuchlik, A., Petrasek, T., Prokopova, I., Bahnik, S., Berger, S., Schonig K., Vales, K., Bartsch, D. (2011). Genetic neurodevelopmental models in biological psychiatry: A study of hippocampusdependent learning in rats with neuronal nogo- a knockdown - Free 
Communication FC-17-002, 10th World Congress of Biological Psychiatry, Prague, http://www.wfsbp-congress.org

Svoboda, J., Telensky, P., Blahna, K., Zach, P., Bures, J., Stuchlik, A. (2008). Lesion of posterior parietal cortex in rats does not disrupt place avoidance based on either distal or proximal orienting cues. Neuroscience Letters, Vol. 445, No. 1, pp. 73-77, ISSN 0304-3940

Swerdlow, N.R., Braff, D.L., Geyer, M.A., Koob, G.F. (1986). Central dopamine hyperactivity in rats mimics abnormal acoustic startle response in schizophrenics. Biological Psychiatry, Vol. 21, No. 1, pp. 23-33, ISSN 0006-3223

Swerdlow, N.R., Weber, M., Qu, Y., Light, G.A., Braff, D.L. (2008). Realistic expectations of prepulse inhibition in translational models for schizophrenia research. Psychopharmacology, Vol. 199, No. 3, pp. 331-388, ISSN 0033-3158

Szechtman, H., Eckert, M.J., Tse, W.S., Boersma, J.T., Bonura, C.A., McClelland, J.Z., Culver, K.E., Eilam, D. (2001). Compulsive checking behavior of quinpirole-sensitized rats as an animal model of Obsessive-Compulsive Disorder(OCD): form and control. BMC Neuroscience, Vol. 2, pp. 4, ISSN 1471-2202

Taube, J.S., Muller, R.U., Ranck, J.B. (1990a) Head direction cells recorded from the postsubiculum in freely moving rats I. Description and quantitative analysis, Journal of Neuroscience, Vol. 10, pp. 420-435, ISSN 0270-6474

Taube, J.S., Muller, R.U., Ranck, J.B. (1990b) Head direction cells recorded from the postsubiculum in freely moving rats II. The effects of environmental manipulations, Journal of Neuroscience, Vol. 10, pp. 436-447, ISSN 0270-6474

Telensky, P., Svoboda, J., Blahna, K., Bureš, J., Kubik, S., Stuchlik, A. (2011). Functional inactivation of the rat hippocampus disrupts avoidance of a moving object. Proceedings of the National Academy of Sciences, USA, Vol. 108, No. 13, pp. 54145418, ISSN 0027-8424

Telensky, P., Svoboda, J., Pastalkova, E., Blahna, K., Bures, J., Stuchlik, A. (2009). Enemy avoidance task: a novel behavioral paradigm for assessing spatial avoidance of a moving subject. Journal of Neuroscience Methods, Vol. 180, No. 1, pp. 29-33, ISSN 0165-0270

Thomsen, M., Wess, J., Fulton, B.S., Fink-Jensen, A., Caine, S.B. (2010). Modulation of prepulse inhibition through both $\mathrm{M}(1)$ and $\mathrm{M}$ (4) muscarinic receptors in mice. Psychopharmacology, Vol. 208, No. 3, pp. 401-416, ISSN 0033-3158

Tordjman, S., Drapier, D., Bonnot, O., Graignic, R., Fortes, S., Cohen, D., Millet, B., Laurent, C., Roubertoux, P.L. (2007). Animal models relevant to schizophrenia and autism: validity and limitations. Behavior Genetics, Vol. 37, No. 1, pp. 61-78, ISSN: 00018244

Ueki, A., Goto, K., Sato, N., Iso, H., Morita, Y. (2006). Prepulse inhibition of acoustic startle response in mild cognitive impairment and mild dementia of Alzheimer type. Psychiatry and Clinical Neurosciences, Vol. 60, No. 1, pp. 55-62, online ISSN 14401819

Vales, K., Stuchlik, A. (2005). Central muscarinic blockade interferes with retrieval and reacquisition of active allothetic place avoidance despite spatial pretraining. Behavioral Brain Research, Vol. 161, No. 2, pp. 238-244, ISSN 0166-4328

Vales, K., Bubenikova-Valesova, V., Klement, D., Stuchlik, A. (2006). Analysis of sensitivity to MK-801 treatment in a novel active allothetic place avoidance task and in the 
working memory version of the Morris water maze reveals differences between Long-Evans and Wistar rats. Neuroscience Research, Vol. 55, No. 4, pp. 383-388, ISSN 0168-0102

Vales, K., Svoboda, J., Benkovicova, K., Bubenikova-Valesova, V., Stuchlik, A. (2010). The difference in effect of mGlu2/3 and mGlu5 receptor agonists on cognitive impairment induced by MK-801. European Journal of Pharmacology, Vol. 639, No. 1-3, pp. 91-98, ISSN 0014-2999

van den Buuse, M. (2010). Modeling the positive symptoms of schizophrenia in genetically modified mice: pharmacology and methodology aspects. Schizophrenia Bulletin, Vol. 36, No. 2, pp. 246-270, ISSN 0586-7614

van der Staay, F.J., Rutten, K., Erb, C., Blokland, A. (2011). Effects of the cognition impairer MK-801 on learning and memory in mice and rats. Behavioral Brain Research, Vol. 220, No. 1, pp. 215-229, ISSN 0166-4328

Van Snellenberg, J.X. (2009). Working memory and long-term memory deficits in schizophrenia: is there a common substrate? Psychiatry Research, Vol. 174, No. 2, pp. 89-96, ISSN 0165-1781

Wesierska, M., Adamska, I., Malinowska, M. (2009). Retrosplenial cortex lesion affected segregation of spatial information in place avoidance task in the rat. Neurobiology of Learning and Memory, Vol. 91, No. 1, pp. 41-49, ISSN 1074-7427

Wesierska, M., Dockery, C., Fenton, A.A. (2005). Beyond memory, navigation, and inhibition: behavioral evidence for hippocampus-dependent cognitive coordination in the rat. Journal of Neuroscience, Vol. 25, No. 9, pp. 2413-2419, ISSN 0270-6474

Woody, E.Z., Szechtman, H. (2011). Adaptation to potential threat: the evolution, neurobiology, and psychopathology of the security motivation system. Neuroscience and Biobehavioral Reviews, Vol. 35, No. 4, pp. 1019-1033, ISSN 01497634

Zeldin, R.K., Olton, D.S. (1986). Rats acquire spatial learning sets. Journal of Experimental Psychology: Animal Behavior Processes, Vol. 12, No. 4, pp. 412-419. ISSN 0097-7403

Zhuravin, I.A., Bures, J. (1991). Extent of the tetrodotoxin induced blockade examined by pupillary paralysis elicited by intracerebral injection of the drug. Experimental Brain Research, Vol. 83, No. 3, pp. 687-690, ISSN 0014-4819 


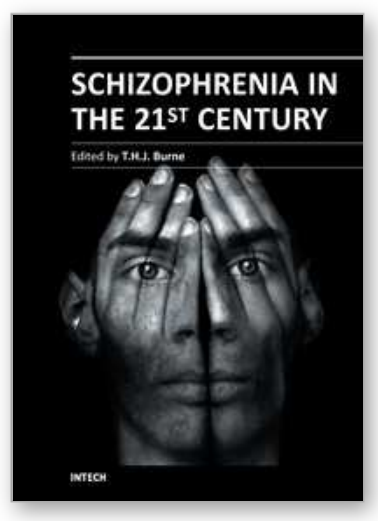

\author{
Schizophrenia in the 21st Century \\ Edited by Dr. T.H.J. Burne
}

ISBN 978-953-51-0315-8

Hard cover, 180 pages

Publisher InTech

Published online 23, March, 2012

Published in print edition March, 2012

Schizophrenia is a poorly understood but very disabling group of brain disorders. While hallucinations and delusions (positive symptoms of schizophrenia) feature prominently in diagnostic criteria, impairments of memory and attentional processing (cognitive symptoms of schizophrenia) are attracting increasing interest in modern neuropsychiatry. Schizophrenia in the 21 st Century brings together recent findings on this group of devastating disorders. We are still a long way from having effective treatment options, particularly for cognitive symptoms, and lack effective interventions and ways to prevent this disease. This volume covers various current options for therapy, clinical research into cognitive symptoms of schizophrenia and preclinical research in animal models.

\title{
How to reference
}

In order to correctly reference this scholarly work, feel free to copy and paste the following:

Ales Stuchlik, Tomas Petrasek, Hana Hatalová, Lukas Rambousek, Tereza Nekovarova and Karel Vales (2012). Behavioral Tests for Evaluation of Information Processing and Cognitive Deficits in Rodent Animal Models of Neuropsychiatric Disorders, Schizophrenia in the 21st Century, Dr. T.H.J. Burne (Ed.), ISBN: 978953-51-0315-8, InTech, Available from: http://www.intechopen.com/books/schizophrenia-in-the-21stcentury/behavioral-tests-for-evaluation-of-information-processing-and-cognitive-deficits-in-rodent-animal-mo

\section{INTECH}

open science | open minds

\author{
InTech Europe \\ University Campus STeP Ri \\ Slavka Krautzeka 83/A \\ 51000 Rijeka, Croatia \\ Phone: +385 (51) 770447 \\ Fax: +385 (51) 686166 \\ www.intechopen.com
}

\author{
InTech China \\ Unit 405, Office Block, Hotel Equatorial Shanghai \\ No.65, Yan An Road (West), Shanghai, 200040, China \\ 中国上海市延安西路65号上海国际贵都大饭店办公楼 405 单元 \\ Phone: +86-21-62489820 \\ Fax: $+86-21-62489821$
}


(C) 2012 The Author(s). Licensee IntechOpen. This is an open access article distributed under the terms of the Creative Commons Attribution 3.0 License, which permits unrestricted use, distribution, and reproduction in any medium, provided the original work is properly cited. 